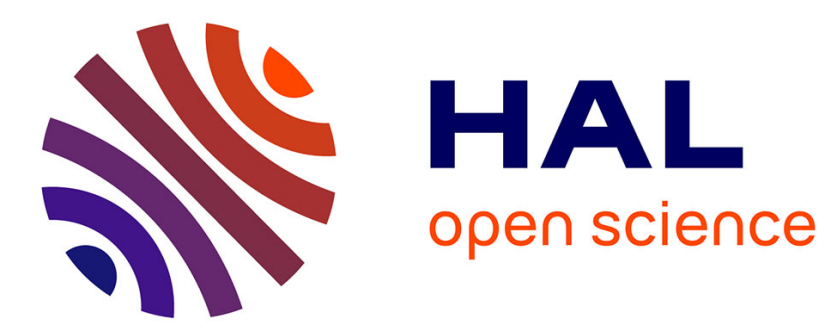

\title{
Coupled electromagnetic acoustic and thermal-flow modeling of an induction motor of railway traction
}

A. Fasquelle, J. Le Besnerais, Michel Hecquet, Souad Harmand, S. Brisset, P. Brochet, A. Randria

\section{- To cite this version:}

A. Fasquelle, J. Le Besnerais, Michel Hecquet, Souad Harmand, S. Brisset, et al.. Coupled electromagnetic acoustic and thermal-flow modeling of an induction motor of railway traction. Applied Thermal Engineering, 2010, 30 (17-18), pp.2788. 10.1016/j.applthermaleng.2010.08.007 · hal-00678800

\section{HAL Id: hal-00678800 https://hal.science/hal-00678800}

Submitted on 14 Mar 2012

HAL is a multi-disciplinary open access archive for the deposit and dissemination of scientific research documents, whether they are published or not. The documents may come from teaching and research institutions in France or abroad, or from public or private research centers.
L'archive ouverte pluridisciplinaire HAL, est destinée au dépôt et à la diffusion de documents scientifiques de niveau recherche, publiés ou non, émanant des établissements d'enseignement et de recherche français ou étrangers, des laboratoires publics ou privés. 


\section{Accepted Manuscript}

Title: Coupled electromagnetic acoustic and thermal-flow modeling of an induction motor of railway traction

Authors: A. Fasquelle, J. Le Besnerais, S. Harmand, M. Hecquet, S. Brisset, P. Brochet, A. Randria

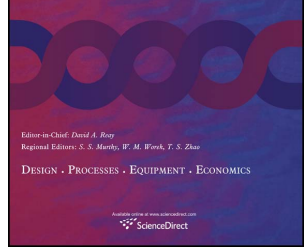

PII:

$$
\text { S1359-4311(10)00327-3 }
$$

DOI: 10.1016/j.applthermaleng.2010.08.007

Reference: ATE 3200

To appear in: Applied Thermal Engineering

Received Date: 4 June 2009

Revised Date: 16 July 2010

Accepted Date: 9 August 2010

Please cite this article as: A. Fasquelle, J. Le Besnerais, S. Harmand, M. Hecquet, S. Brisset, P. Brochet, A. Randria. Coupled electromagnetic acoustic and thermal-flow modeling of an induction motor of railway traction, Applied Thermal Engineering (2010), doi: 10.1016/j.applthermaleng.2010.08.007

This is a PDF file of an unedited manuscript that has been accepted for publication. As a service to our customers we are providing this early version of the manuscript. The manuscript will undergo copyediting, typesetting, and review of the resulting proof before it is published in its final form. Please note that during the production process errors may be discovered which could affect the content, and all legal disclaimers that apply to the journal pertain. 


\title{
Coupled electromagnetic acoustic and thermal-flow modeling of an induction motor of railway traction
}

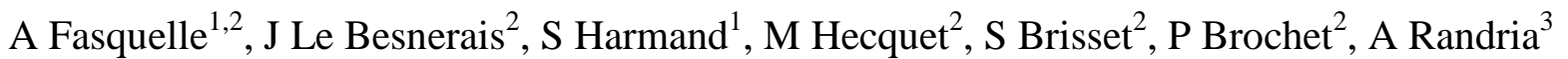 \\ (Corresponding author: souad.harmand@univ-valenciennes.fr) \\ ${ }^{1}$ Université Lille Nord de France, F-59000 Lille, UVHC, TEMPO, F-59313 Valenciennes, \\ France \\ ${ }^{2}$ Laboratoire d'Electrotechnique et d'Electronique de Puissance (L2EP), Ecole Centrale de Lille, Cité \\ Scientifique, BP48, 59651 Villeneuve d'Ascq, France \\ ${ }^{3}$ Alstom Transport, 7 avenue de Lattre de Tassigny, BP 49, 25290 Ornans, France
}

\begin{abstract}
In order to optimize the design of an enclosed induction machine of railway traction, a multiphysical model is developed taking into account electromagnetic, mechanical and thermal flow phenomena. The electromagnetic model is based on analytical formulations and allows calculating the losses. The thermal flow modeling is based on an equivalent thermal circuit which has the feature to consider the flow structure inside the machine. In this way, a numerical study has been carried out to evaluate this internal flow structure depending on the rotational speed. The results of the multi-physical model are confronted with experimental results.
\end{abstract}

\section{Nomenclature}

$\varepsilon \quad$ Emissivity or Dissipation rate of turbulent $k$ kinetic energy, $\mathrm{m}^{2} \cdot \mathrm{s}^{-3}$

Heat Flux density, W. $m^{-2}$

$\sigma \quad$ Stephan-Boltzmann constant, $\sigma=5.67 \cdot 10^{-8} W \cdot m^{-2} \cdot K^{4}$

$\Lambda \quad$ Permeance per unit area, $H . m^{-2}$

$B_{g} \quad$ Radial air-gap flux density, $T$

$C p \quad$ Specific heat capacity, $J \cdot \mathrm{kg}^{-1} \cdot K^{-1}$

$f_{\text {tmm }}$ Total magnetomotive force, $A$

$h \quad$ Convective heat transfer coefficient, $W \cdot m^{-2} \cdot K^{-1}$
Turbulent kinetic energy, $\mathrm{J}_{\mathrm{kg}} \mathrm{g}^{-1}$

Mass flow rate, $k g . s^{-1}$

Area, $m^{2}$

Temperature, $K$

\begin{tabular}{ll}
\multicolumn{2}{l}{ Subscripts } \\
en & Entrance \\
ex & Exit \\
ref & Reference \\
$w$ & Wall
\end{tabular}

\section{1 - Introduction}

For the past few years, the major development of transports has been followed by growing concern for the respect of environment. Although railway transports have high energy efficiency, they also cause environmental hazards. It is then necessary to include the sustainable development from the moment of conception. It results in the consideration of numerous physical phenomena. Indeed, it is nonsense to consider each phenomenon separately: the electromagnetic optimum often differs from the thermal optimum, and vice 
versa. Consequently, this study aims at emphasizing a conception methodology in the respect to the current will of economic and ecological optimization. Then, a multi-physical model has been developed in order to represent electromagnetic and thermal-flow phenomena in an enclosed induction motor of railway traction. This paper focuses on the thermal flow part of this multi-physical model.

Numerous multi-physical models of electrical machines have been developed for the past few years. Most of them are based either on Finite-Element modeling [1] [2] or on analytical modeling [3] [4]. Although the model used for the optimization needs to meet a good compromise between calculation time, accuracy and malleability. As far as the electrical machines are concerned, the commonly used thermal approach is the equivalent thermal circuit. Models in literature are quite simple and consider simplified geometry. For instance, Puranen and al. [4] represent in their thermal model the induction motor as a cylinder. Then, the resulting temperatures correspond to mean values and no local information are available. The equivalent circuit in this study is finer than models in literature. Moreover, it takes into account the flow structure inside the machine.

The motor studied in this paper is a railway traction induction motor with a squirrel cage. This kind of motor is mainly used in subways and electric tramways. The power of this motor is $210 \mathrm{~kW}$ and the maximum rotational speed is $4500 \mathrm{rpm}$. In this enclosed motor, the air is imprisoned into the machine: it is never renewed. In order to allow air to circulate within the motor, a fan is attached to the shaft in one cavity and several ducts are bored into the rotor and the stator yoke. Then, some fresh air, propelled by an external fan, can circulate into these ducts (Figure 1). The flow structure in this kind of motor is particularly complex due to the confinement and the rotation. To be able to take into account this flow, a numerical study of fluid flow is carried out and is presented in the following paragraph. This numerical study also permits to determine some missing convective heat transfer coefficients.

Then, the multi-physical model is described. In the fourth part, it is validated in comparison with experimental tests. Finally, a sensitivity study is presented.

\section{2 - Numerical study of fluid flow}

The numerical study has been firstly carried out with the CFD code Fluent $\odot$ v.6.2 [5]. Three different rotational speeds $(1500,2200$ and $4000 \mathrm{rpm})$ have been imposed in the simulations.

\subsection{Numerical model}

In theory, the Navier-Stokes equations perfectly describe the laminar and turbulent flows. But, in order to avoid solving the whole turbulence scales and then to reduce the computing time, the equations can be statistically averaged by introducing mean and fluctuating quantities. Then, the Reynolds Averaged Navier-Stokes (RANS) equations are obtained. They are similar to the original equations but some unknown additional terms of turbulence appear. These terms, called the Reynolds stresses or turbulent stresses, represent the fluctuating components of the turbulent flow and need to be modelled by additional equations: it is the "closure problem". Various turbulence models are available with different complexity levels and specific features. The turbulence model which is used in this study is a model with two closing equations: the standard $k \varepsilon$ model [5]. It presents two additional transport equations: one is concerning $k$ the turbulent kinetic energy and the other one is relating to $\varepsilon$ the dissipation rate of this energy. 
An unsteady implicit formulation is applied. The discretization models are the standard model for pressure and first order upwind for the other equations. The shape of the grid close to walls imposes to use the standard wall functions: then, the viscosity-affected region is not resolved, instead, semi-empirical formulas are used to link the viscosity-affected region between the wall and the fully turbulent region.

The sliding mesh technique had been applied in this study for the modelling of the air gap flow. This modelling consists in creating two distinct zones: one is linked to the rotor and the other one is attached to the stator. Both zones can slip on each other according to a grid interface. Consequently, an unsteady computation is carried out: after each time step, the rotor has slipped along the stator. This method enables to take into account unsteadiness resulting from rotation.

The transient feature of this method results in a very expensive computing time. Approximately five and a half days in term of CPU time are necessary to carry out 1000 time steps by parallel processing using 8 processors (HP alphaserver GS1280 / 16 processors alpha EV7 - 1.15 Ghz / 32 Go memory).

For symmetry reasons, the geometry can be limited to the quarter of the motor. As the interest lies in the flow structure, only air zones have been modeled. In order to ease the mesh construction and to improve the computing times, the whole curved profiles have been replaced by straight forms (Figure 2). Only the fan and the air-gap, irregular by the presence of the slots openings, have been kept as they are in the real motor. The whole geometry gathers approximately 2300000 elements.

\subsection{Flow fluid results}

The flow structure into the enclosed motor is established for the three rotational speeds $(1500$, 2200 and $4000 \mathrm{rpm}$ ). Air comes into the cavity with fan by the ducts in rotor, which means at the bottom of the fan. This one propels the air on the end windings. Then, air circulates above them and goes to the air-gap by the straight part of the end windings. Then, the main air flow comes into the end region without fan by the air-gap. Joining by rotating air, it crosses coils in spaces close to the stator. Then, it circulates above the end windings before joining the ducts in rotor. In both cavities, important swirls can be observed in the center of cavities and above the coils. These swirls above the end windings go to set several problems from a thermal point of view (figure $3 \mathrm{a} / \mathrm{b}$ ).

This flow structure is similar for the three rotational speeds which have been tested. However, sizes of swirls vary slightly with speed. In the same way, the mass flow rates circulating into the motor, and consequently the air velocity, vary with rotational speed. The Table 1 presents main mass flow rates which can be observed in the machine.

The velocity distribution in the air-gap is not uniform. Indeed, high velocity appears in rotor slot openings (more than $34 \mathrm{~m} / \mathrm{s}$ for a rotational speed of $2200 \mathrm{rpm}$ ) and very slow velocity appears in stator slot openings (less than $6 \mathrm{~m} / \mathrm{s}$ for a rotational speed of $2200 \mathrm{rpm}$ ). In the same way, the mass flow is unequally distributed in the air-gap. The main part of mass flow rate (between $66 \%$ and $71 \%$ ) circulates in the stator slot openings. A small part of the mass flow rate circulates in the rotor slot (between 6 and 8\%). It has to be noticed that the air tends to exit the rotor slot openings due to the centrifugal effect. 
Some thermal simulations have been carried out in the end regions to compute the convective heat transfer coefficients. Indeed, the literature is quite poor regarding these geometries. Thermal simulations need finer grid, especially close to walls to well estimate convective heat transfers. The boundary conditions on flow inlet and outlet are defined thanks to previous results [6]. Some temperatures, inspired by usual observed temperature in previous experiments, have been imposed to walls $\left(T_{w}\right)$. The simulations estimate the convective heat transfers. Then, from the resulting heat flux density $\varphi$, it is possible to estimate the convective heat transfer coefficients $h$ (Equation 1).

$$
\varphi=h \cdot\left(T_{w}-T_{r e f}\right)
$$

The reference temperature $T_{r e f}$ is defined as an averaged temperature by zones. These zones correspond to the air elements defined in the thermal-flow model [6]. For instance, the Figure 3.c presents the heat flux density which is obtained on the end windings in the cavity with fan for the rotational speed of $2200 \mathrm{rpm}$. The distribution appears quite homogenous except in zones close to fan and close to the straight parts of the end windings. In these areas, the flux density can be multiplied by 5 in comparison with the mean flux density. It can also be noticed that the heat flux density is negative on the lower part of the end windings (close to rotor copper). This means that this area is not cooled but instead it is warmed by the air.

\section{$\underline{3 \text { - Multi-physical model }}$}

The multi-physical model is divided into two main models connected to each other: an electromagnetic model and a thermal-flow model. The models and their coupling are described in details in the following paragraphs.

\subsection{Electromagnetic model}

The electromagnetic model computes the air-gap radial flux density, and the losses inside the machine, which are the thermal sources. Stator and rotor currents computation is based on an extension of the classical single phase equivalent circuit, including all space and time harmonics and the skin effect modelling [7]. Total magnetomotive force $f_{\text {tmm }}$ is computed using winding functions [8] with linear rise in slots and constant value in teeth. Permeance per unit area $\Lambda$ is then computed and radial air-gap flux density $B_{g}$ is obtained as the product of $\Lambda$ and $f_{\text {tmm }}$ [9]. Air-gap radial flux-density shape has been validated in comparison with the Finite Elements software Flux2D@e.

Iron losses are modeled with analytical formulas established from numerical results (with the Finite Elements software Flux2D(C). These losses are present in the whole stator (teeth and yoke) and at the surface of the rotor. It has to be noticed that the rotor surface stray losses are significant. It could represent until $35 \%$ of the total iron losses [10]. This observation also appears in [11] and [12]. More details about the numerical study and the resulting analytical formulas can be found in [10] and [6].

\subsection{Thermal-flow model}

The thermal-flow model computes the evolution in time of temperatures in the motor. This model is based on an equivalent thermal circuit which has the distinctive feature to consider the flow structure inside the machine. 
The machine is devised into eleven sections axially and each section can have different radial division resulting to a total of 126 volumes for the whole machine (fig. 4). The definition of the volumes is based both on materials data and on our numerical flow study. A mass flow cartography is then included in the model. It is a bi-dimensional cartography which takes into account the main air flow crossing the motor and rotating structures in both cavities, described in paragraph 2.2 (fig. 3).

The power balance on volumes results in a system of coupled numerical equations. This system can be expressed with matrix (Equation 2) where $\boldsymbol{T}$ and $\boldsymbol{P}$ are respectively the temperatures and losses/heat evacuations vectors, $\boldsymbol{C}$ is the heat capacities matrix and $\boldsymbol{G}$ is the thermal conductances matrix. Three kinds of transfers are considered: conduction, convection and fluid transfers.

$$
C \cdot \frac{d T}{d t}=G \cdot T+P
$$

Some heat transfer coefficients can be expressed from literature, especially in the air-gap [13]. But the literature is quite poor regarding regions as end regions. That is why thermal numerical simulations have been carried out to determine the missing data.

The coupled problem is solved in successive steps and the coupling is performed by up-dating and transferring some new values for the depending parameters before solving again.

\section{4 - Results and analysis}

\subsection{Experimental investigation}

Series of experiments have been carried out on a real machine with several kinds of operation conditions:

- The machine has been towed away by an other motor for several rotational speeds. Then, only the mechanical losses appear.

- No-load test has been carried out for a rotational speed of $3010 \mathrm{rpm}$. In this kind of experiments, few losses appear in addition of mechanical losses: iron losses and losses caused by the Joule effect in stator coppers.

- Load operation conditions for rotational speeds: 1500, 2200, 3010 and 3500 rpm have been tested. Significant losses appear in the whole motor: mechanical, iron and Joule losses.

Experimental losses are presented in table 2.

Some electrical measurements are available (rotational speed, slip, voltage, stator current, power factor, input power). The torque, the output power and the efficiency are deduced from torquemeter measurements. Moreover, several thermal and flow sensors have been fitted into the machine.

- Sixty thermocouples are situated in the whole motor: in air and materials, in the stationary and rotating parts.

- Three heat flux sensors have been placed on the external walls: on both end shields and on the external side of stator yoke.

- An infrared camera has been placed so as to evaluate the surface temperatures of the stator yoke and of one of the end shield (the one located towards the internal fan).

- A hot wire sensor can be inserted into the machine through openings in end shields, and permits to estimate the air velocity above the end windings.

\subsection{Model validation}


The motor performances in variable-speed have been also checked [7]. It is observed that the stator current, the torque, the output power, the power factor and the efficiency are well estimated by the electromagnetic model, within $5 \%$ of error from the experimental results. The mechanical losses and the losses caused by Joule effect are also well estimated (within $4 \%$ of error) but a significant error can be observed in the estimation of iron losses. This error of about $50 \%$ and could results from an error in the characteristic of the flux density of the material.

The Figure 5 presents the evolution of temperatures in the magnetic circuits for both experimental data and model results in load operation conditions at the rotational speed of $2200 \mathrm{rpm}$. A temperature gradient exists in the stator magnetic circuit due to the fact that the stator ducts are not equitably distributed in the stator. The temperature gradient on the external walls can easily reach $60^{\circ} \mathrm{C}$ in steady state.

The rotor electrical sheets are much warmer than the stator ones (Figure 5). This trend is respected by the model but the estimated difference of temperatures between both parts is smaller. Indeed, the rotor temperature is under-estimated and the stator temperature is overestimated of about respectively $30^{\circ} \mathrm{C}$ and $70^{\circ} \mathrm{C}$ in steady state. This reduces the difference until $55^{\circ} \mathrm{C}$ instead of the experimental difference of $158^{\circ} \mathrm{C}$ in steady state.

As far as the coppers are concerned, the resulting steady-state temperatures of the model are compared with the experimental results in the Table 3 . The temperatures of the rotor coppers are quite well estimated by the model. It has to be noticed that the copper towards internal fan is warmer than copper towards external fan. This trend can be observed in the whole machine and is respected in the model.

Three kinds of heat fluxes are evaluated: forced convection in stator ducts, natural convection (with the measurements of the heat flux sensors), radiation and conduction into the shaft (Equation 3) on the external walls. The conduction through the shaft cannot be estimated experimentally. The balance of these three fluxes corresponds to the total losses within $15 \%$.

$$
P_{\text {stator_ducts }}=q_{m} \cdot C_{p} \cdot\left(T_{e x}-T_{e n}\right) \quad P_{\text {radiation }}=\varepsilon \cdot \sigma \cdot S \cdot\left(T_{w}^{4}-T_{\infty}^{4}\right)
$$

The distribution of the experimental heat fluxes are presented in the Table 4 in terms of percentage. The largest part of the heat evacuation, about $90 \%$, is assigned to the convection into the stator ducts. It has to be noted that the radiation evacuates few heat.

The air velocity measurements aim at validating the numerical simulations. The available measurements to compare the numerical and experimental results are velocity measurements above the end windings in both cavities (Figure 6). The order of magnitude and the evolution seem to be well estimated by the numerical simulations and the highest velocities are located in the cavity with the internal fan.

\subsection{Sensitivity analysis}

The sensitivity study is focuses on modifications in heat transfers. The results from modifications are compared with the model results in the same conditions thanks to the temperatures differences for the steady state (Equation 4).

$$
\Delta T=T_{\text {modifications }}-T_{\text {reference }}
$$


The Figure 7 presents temperatures distributions resulting from a modification of the coefficient by $-80 \%$ and $-100 \%$ on the rotor copper in the cavity with fan. This latter modification could be the result of a complete insulation of the copper in this cavity.

Both modifications imply similar results but the trends are more outstanding where the insulation is complete. The air temperature close to rotor copper highly decreases (about $10^{\circ} \mathrm{C}$ and $-20^{\circ} \mathrm{C}$ for the modifications of $-80 \%$ and $-100 \%$ respectively). This involves a reduction of the temperature of the internal air in the whole machine. Then, the evacuation of heat can be increased and the temperatures into the machine decrease for a small increase of the rotor copper temperature (about $+1{ }^{\circ} \mathrm{C}$ and $+1.2^{\circ} \mathrm{C}$ for the modifications of $-80 \%$ and $100 \%$ respectively). Even if the temperatures vary with the heat transfer coefficients modifications, the observed discrepancies are not significant and do not have an impact on the heat fluxes distributions.

\subsubsection{External conditions}

So far, the external walls of the magnetic sheets and the end shield towards the internal fan have been exposed to natural convection with a convective heat transfer coefficient of $5 \mathrm{Wm}^{-}$ ${ }^{2} \mathrm{~K}^{-1}$. This one is increased until 10 and $15 \mathrm{Wm}^{-2} \mathrm{~K}^{-1}$. This modification has a significant impact on temperature distribution in steady state (Figure 8). Temperatures of stator and rotor sheets decrease of about 15 and $30^{\circ} \mathrm{C}$.

Despite the fact that the temperature decrease is more important in the cavity with fan, this cavity remains warmer than the other cavity. Nevertheless, the temperature differences between both cavities decrease. For instance, the temperature discrepancy between both cavities for the end windings decreases from $11.3{ }^{\circ} \mathrm{C}$ to $6^{\circ} \mathrm{C}$ for convective heat transfer coefficients of 5 and $15 \mathrm{Wm}^{-2} \mathrm{~K}^{-1}$ respectively. In the same way, the temperature discrepancy between both cavities for the rotor copper decreases from $18.9^{\circ} \mathrm{C}$ to $16.3^{\circ} \mathrm{C}$.

\section{$\underline{5 \text { - Conclusion }}$}

A multi-physical model has been developed in order to realize the optimal conception of an enclosed induction motor of railway traction. This model is divided into two parts: the electromagnetic model evaluates the radial flux density in the air-gap, such as iron losses, the thermal-flow model is based on a thermal equivalent circuit. This one takes into account the flow structure inside the motor, which has been the purpose of a specific numerical study.

The results of the multi-physical model have been compared with experimental results for variable speeds and loads. This reveals that the multi-physical model respects the experimental trends even if some temperatures have to be readjusted. Then, a sensitivity study has been carried out. It shows the significant part of the internal mass flow to homogenize temperatures inside the motor.

The thermal-flow modeling can be improved. Indeed, even if the model predicts the good trends, some levels have to be modified. To do so, the representation of some parts of the machine can be refined in the thermal equivalent circuit, such as the stator coppers or the bearings. Moreover, some contact resistances can be taken into account. When these modifications are realized, the multi-physical model could be used with an optimization process. It could also be used in a different way: it could help identifying the losses inside the machine and their localizations thanks to an inverse method. 


\section{Acknowledgement}

This work was undertaken as part of the CNRT (National Center for Technology Research) Futurelec program. The authors would like to thank the French Education Ministry, the NordPas-De-Calais region, the EU (FEDER) and Alstom Transport for their financial support.

\section{References}

[1] $\mathrm{P}$ K Vong, D Rodger, Coupled electromagnetic-thermal modeling of electrical machines, IEEE Transactions on Magnetics, Vol 39, n³, 2003, pp. 1614-1617

[2] J Driesen, R J M Belmans, K Hameyer, Methodologies for coupled transient electromagnetic-thermal Finite-element modeling of electrical energy transducers, IEEE Transactions on industry applications, Vol 38, n5, 2002, pp.1244-1250

[3] K Nakaruma, H Yoshida, O Ichinokura, Electromagnetic and thermal coupled analysis of ferrite orthogonal-core based on three-dimensional reluctance and thermal-resistance network model, IEEE Transactions on magnetics, vol 40, n²4, 2004, pp. 2050-2052

[4] J Puranen, J Pyrhönen, dynamic thermal analysis of an induction servomotor with a coupled electromagnetic-thermal model, XVII International Conference on Electrical Machines, Crete Island, Greece, September 2006, paper $n^{\circ} 160$

[5] Fluent v.6.0, User's guide (2001)

[6] A Fasquelle, Contribution à la modélisation multi-physique : électro-vibro-acoustique et aérothermique de machines de traction, PhD Thesis, Ecole Centrale de Lille, November 2007

[7] J Le Besnerais, A Fasquelle, M Hecquet, V Lanfranchi, P Brochet, A fast noisepredictive multiphysical model of the PWM-controlled induction machine, Proc. of the International Conference on Electrical Machines (ICEM'06), Chania, Greece, July 2006

[8] A Ghoggal, M Sahraoui, A Aboubou, S Zouzou, H Razik, An improved model of the induction machine dedicated to faults detection - extension of the modified winding function approach, Proc. of the International Conference on Industrial Technology, Dec. 2005, pp. 191-196

[9] G Bossio, C D Angelo, J Solsona, G Garcia, M Valla, A 2-D model of the induction machine: an extension of the modified winding function approach, IEEE Trans. on Energy Conversion, vol. 19, no. 1, Mar. 2004

[10] A Fasquelle, A Ansel, S Brisset, M Hecquet, P Brochet A Randria, Iron losses distribution in a railway traction induction motor, Proc. of the International Conference on Electrical Machines (ICEM'06), paper n ${ }^{\circ}$ 00, Chania, Greece, July 2006

[11] R Romary, J Ninet, JF Brudny, Procedure to analyse the slotting effect in the total iron losses of induction machine, International Electric Machines and Drives Conference 2001 (IEMDC 2001), 17-20 june 2001, Cambridge, Massachussets, pp.280-284

[12] T Chevalier, A Kedous-Lebouc, B Cornut, C Cester, Estimation of magnetic loss in an induction motor fed with sinusoidal supply using finite element software and a new approach to dynamic hysteresis, IEEE Trans on Magnetics, Vol. 35, n5, Sept. 1999

[13] M Bouafia, Y Bertin, J B Saulnier, Analyse expérimentale des transferts de chaleur en espace annulaire étroit et rainuré avec cylindre intérieur tournant, International Journal of Heat and Mass Transfer, Vol. 41, n 10, pp. 1279-1291, 1998 




FIGURE 1 Machine description

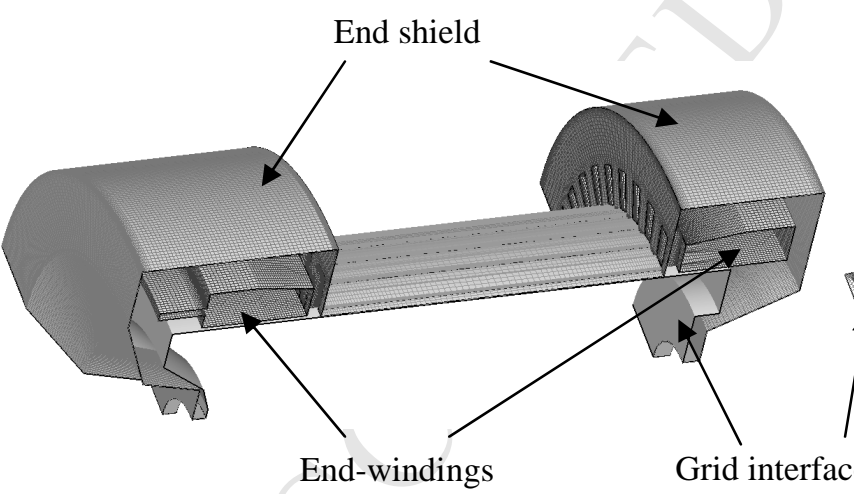

a) Stationary part

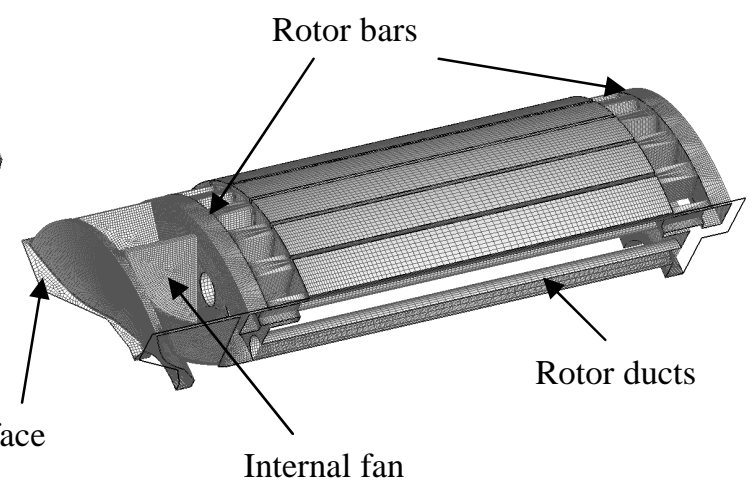

b) Rotating part

FIGURE 2 Geometry set-up - numerical study of fluid-flow 


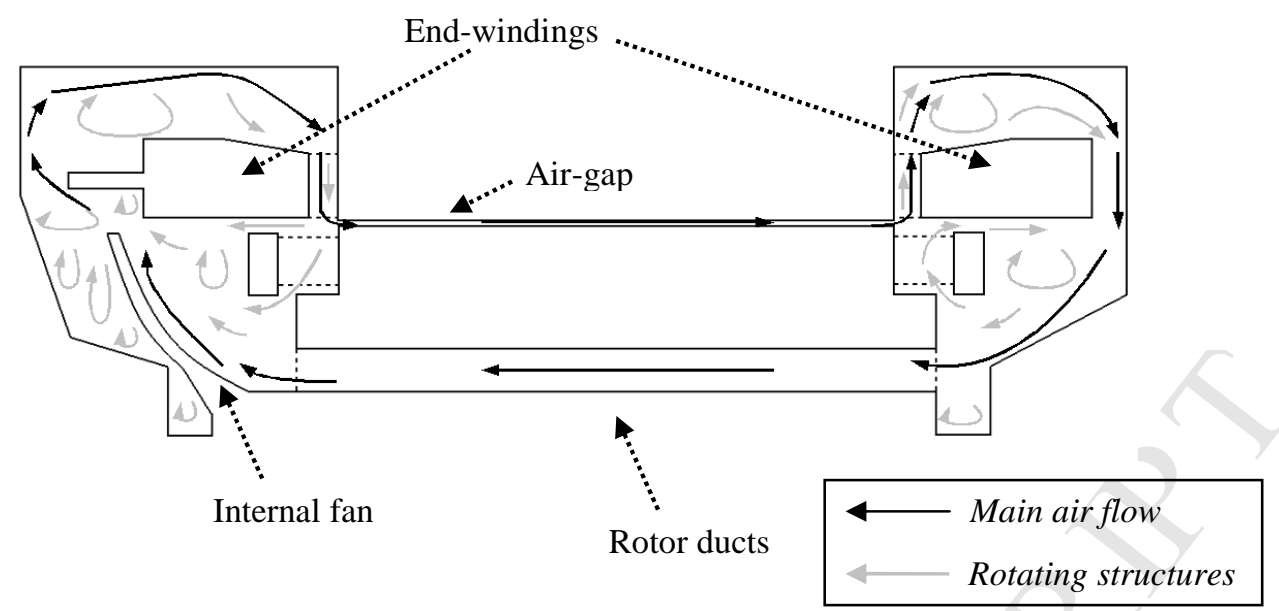

a) Schematic flow structure

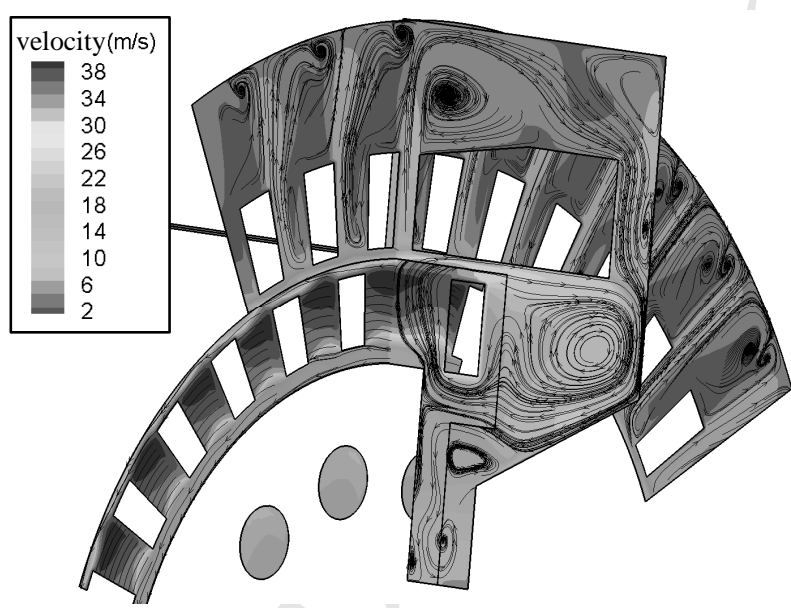

b) Streamlines in the cavity without fan - $2200 \mathrm{rpm}$

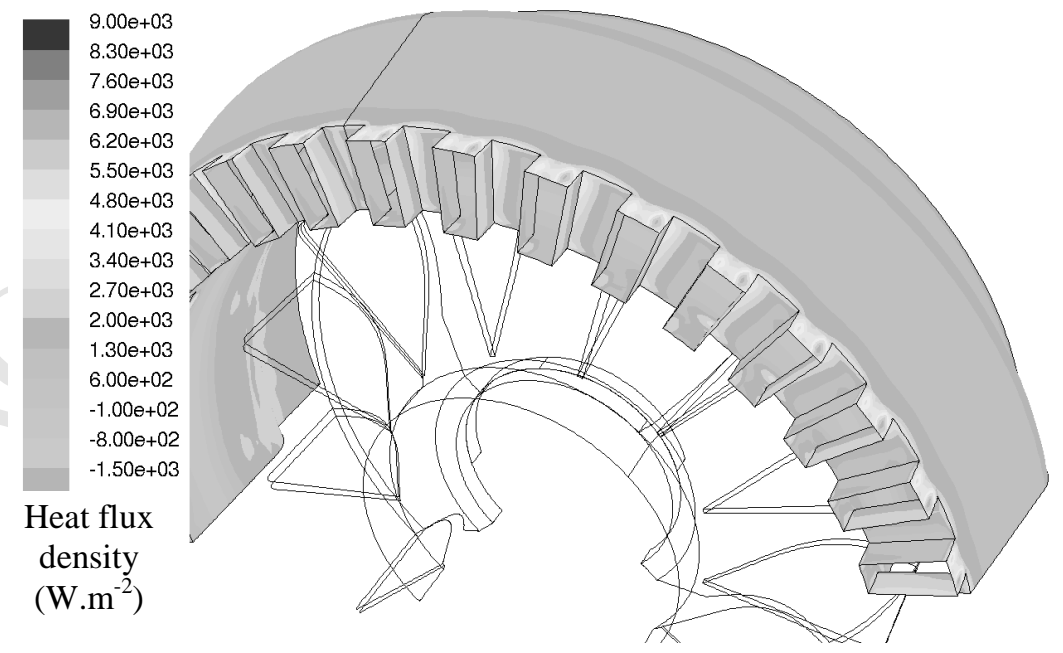

(c) Heat flux density on the end-windings in the cavity with fan-2200 rpm

FIGURE 3 Flow structure and heat transfer within the machine 


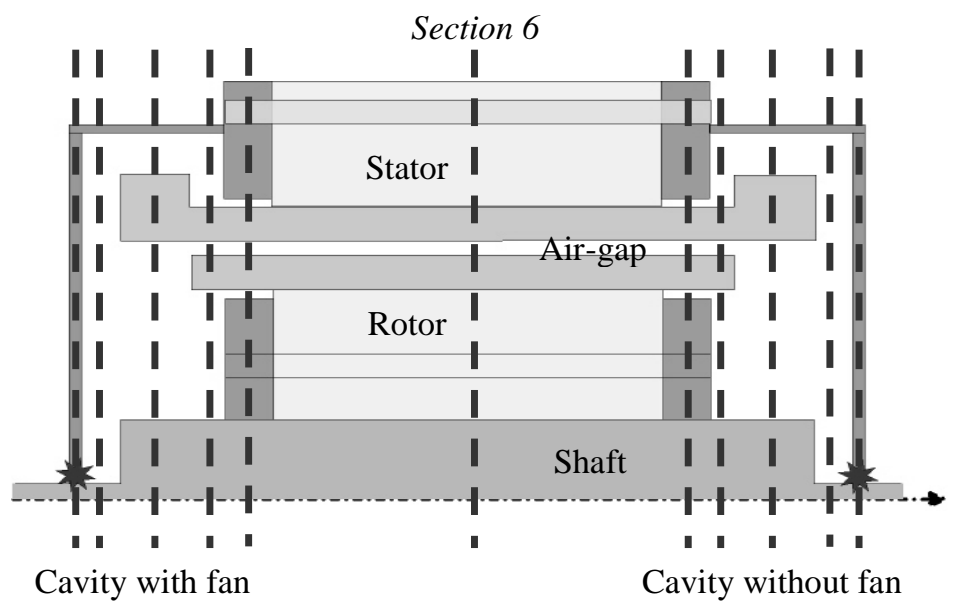

a) Axial division

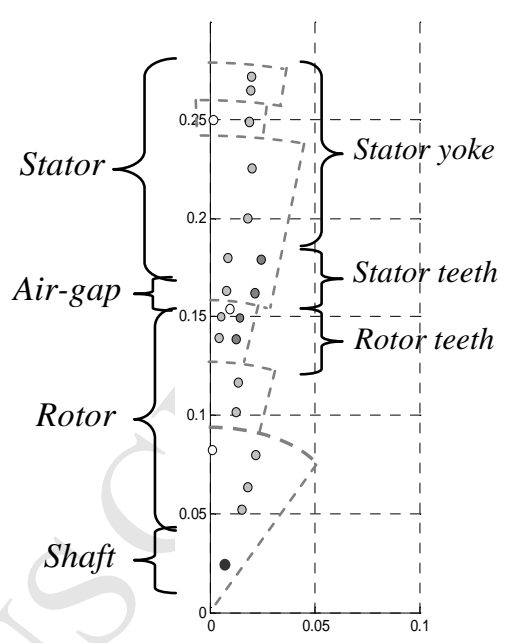

b) Exemple of radial division (section 6)

FIGURE 4 Thermal flow model: Division of the machine into volumes

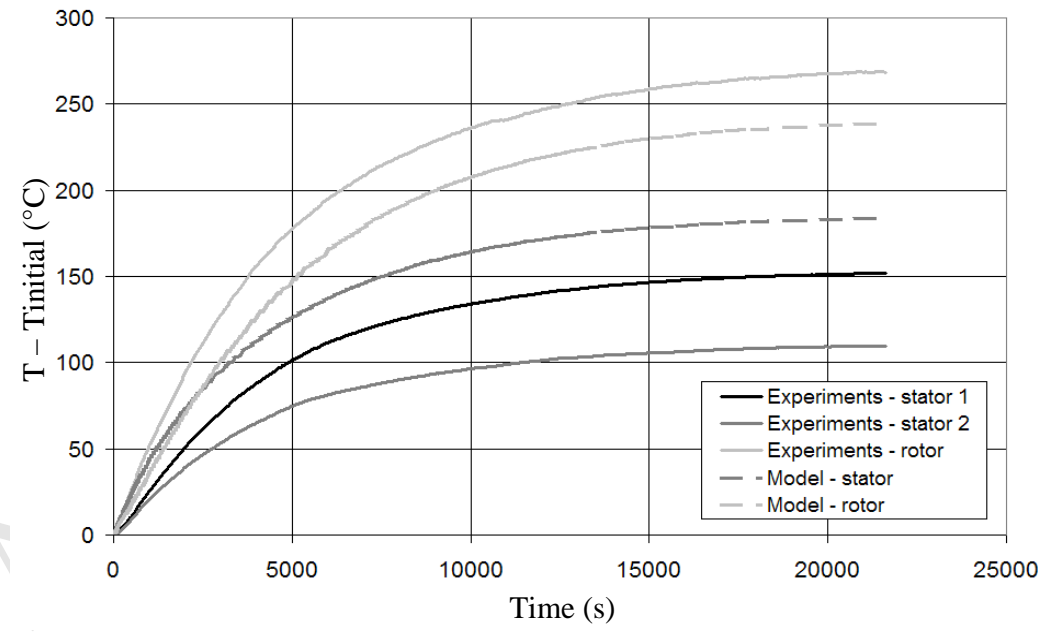

FIGURE 5 Evolution of temperatures in electrical sheets

(Stator1: measurement far from stator ducts, Stator 2: measurement close to stator ducts) 


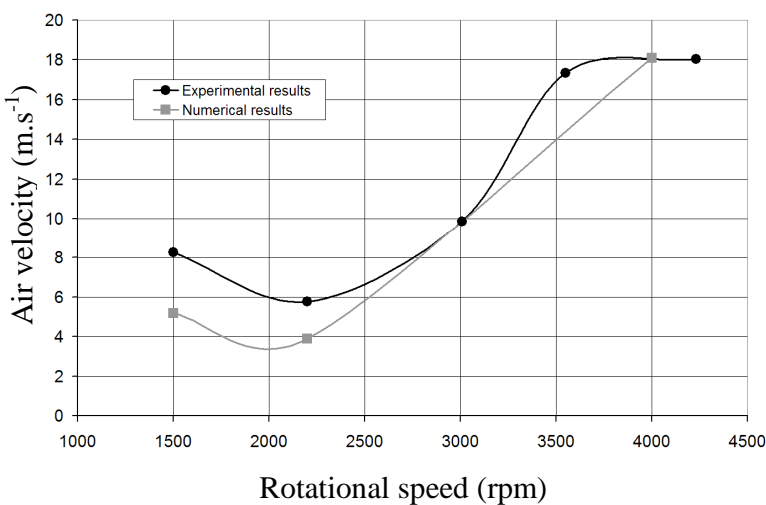

a) Cavity with fan

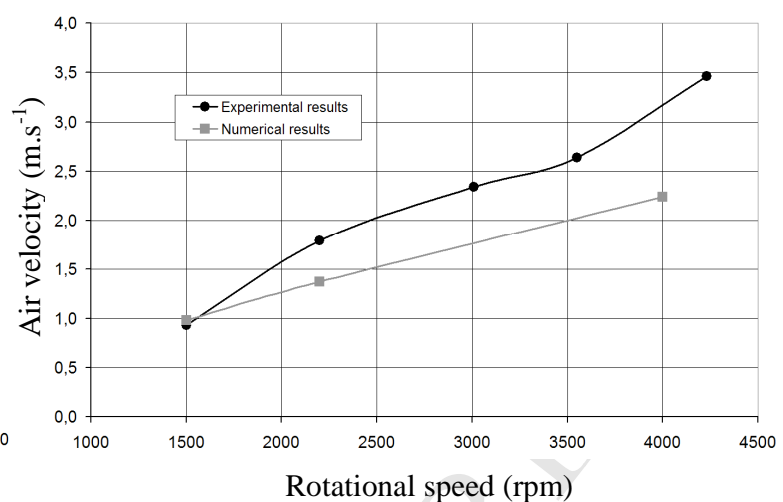

b) Cavity without fan

FIGURE 6 Comparison of air velocity between experiments and numerical study

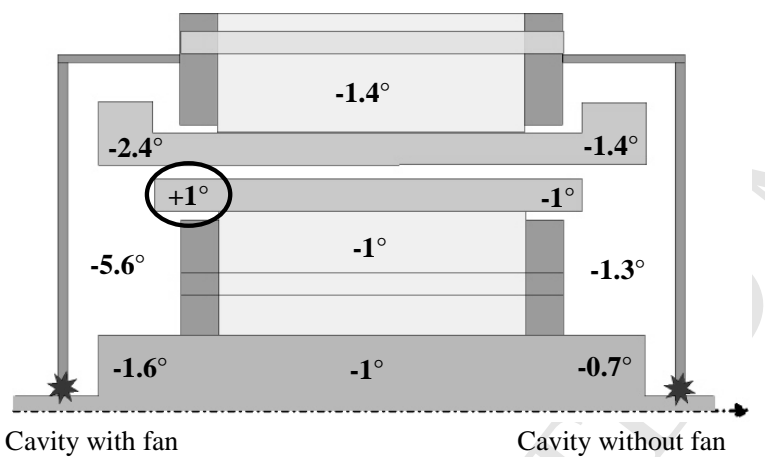

a) Decrease by $80 \%$

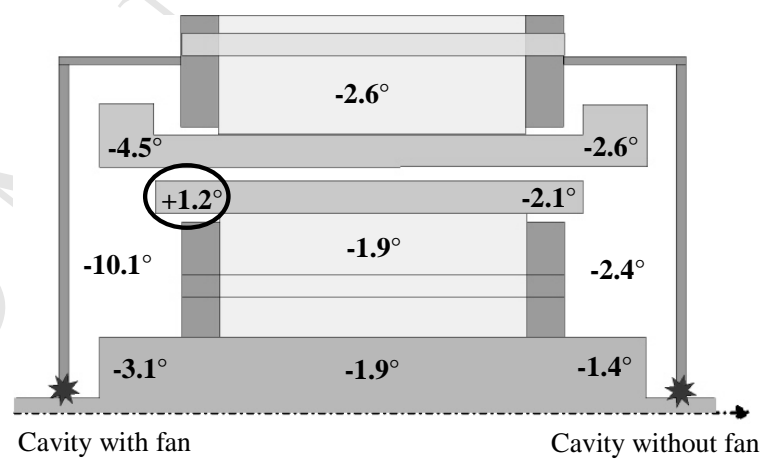

b) Decrease by $100 \%$

FIGURE 7 Temperature distributions resulting from the modification of the convective heat transfer coefficient on the rotor copper in the cavity with fan 

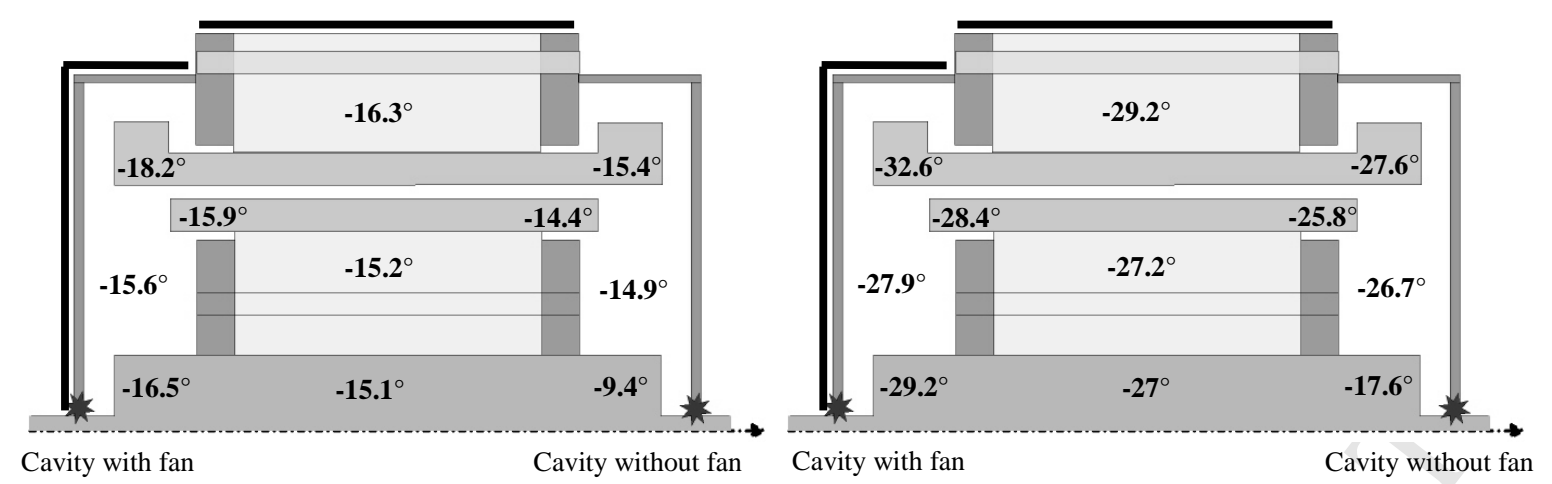
a) $h_{e x t}=10 \mathrm{~W} \cdot \mathrm{m}^{-2} \cdot \mathrm{K}^{-1}$
b) $h_{e x t}=15 W \cdot m^{-2} \cdot K^{-1}$

FIGURE 8 Temperature distributions resulting from the modification of the convective heat transfer coefficient on the external walls 


\begin{tabular}{|c|c|c|c|c|}
\hline \multicolumn{2}{|c|}{ Rotational speed (rpm) } & 1500 & 2200 & 4000 \\
\hline Variation range of air velocity $(\mathrm{m} / \mathrm{s})$ & $0-25$ & $0-36$ & $0-65$ \\
\hline \multirow{3}{*}{$\begin{array}{c}\text { Cavity } \\
\text { with fan }\end{array}$} & Mass flow rate crossing the air-gap $(\mathrm{kg} / \mathrm{s})$ & 0.010 & 0.018 & 0.038 \\
\cline { 2 - 5 } & Mass flow rate crossing the end windings $(\mathrm{kg} / \mathrm{s})$ & 0.028 & 0.036 & 0.082 \\
\cline { 2 - 5 } & Mass flow rate crossing the rotor bars $(\mathrm{kg} / \mathrm{s})$ & 0.011 & 0.016 & 0.023 \\
\hline \multirow{2}{*}{$\begin{array}{c}\text { Cavity } \\
\text { without fan }\end{array}$} & Mass flow rate circulating between coils $(\mathrm{kg} / \mathrm{s})$ & 0.007 & 0.002 & 0.021 \\
\cline { 2 - 5 } & Mass flow rate crossing the end windings $(\mathrm{kg} / \mathrm{s})$ & 0.017 & 0.023 & 0.032 \\
\cline { 2 - 5 } & Mass flow rate crossing the rotor bars $(\mathrm{kg} / \mathrm{s})$ & 0.035 & 0.050 & 0.031 \\
\cline { 2 - 5 } & 0.028 & 0.045 & 0.039 \\
\hline
\end{tabular}

TABLE 1 Mass flow rates in the enclosed machine - numerical results

\begin{tabular}{|c|c|c|c|c|c|c|}
\hline \multirow{2}{*}{$\begin{array}{l}\text { Operation } \\
\text { conditions }\end{array}$} & \multirow{2}{*}{$\begin{array}{c}\text { Rotational } \\
\text { speed (rpm) }\end{array}$} & \multicolumn{2}{|c|}{$\begin{array}{c}\text { Losses caused by Joule } \\
\text { effect (W) }\end{array}$} & \multirow{2}{*}{$\begin{array}{l}\text { Mechanical } \\
\text { losses }(\mathrm{W})\end{array}$} & \multirow{2}{*}{$\begin{array}{l}\text { Total iron } \\
\text { losses (W) }\end{array}$} & \multirow{2}{*}{$\begin{array}{c}\text { Total losses } \\
(\mathrm{kW})\end{array}$} \\
\hline & & Stator & Rotor & & & \\
\hline \multirow{4}{*}{ Load } & 1500 & 2929 & 1503 & 387 & 5059 & 9.88 \\
\hline & 2200 & 3185 & 2742 & 1132 & 3294 & 10.35 \\
\hline & 3010 & 3317 & 3082 & 2489 & 2588 & 11.48 \\
\hline & 3500 & 2672 & 2486 & 3755 & 2353 & 11.27 \\
\hline No-load & 3010 & 169 & 0 & 2489 & 2588 & 5.25 \\
\hline
\end{tabular}

TABLE 2 Experimental losses

\begin{tabular}{|c|c|c|c|c|c|}
\hline & & Cavity & $\begin{array}{l}\text { Experimental } \\
\text { results }\left({ }^{\circ} \mathrm{C}\right)\end{array}$ & $\begin{array}{l}\text { Model results } \\
\qquad\left({ }^{\circ} \mathrm{C}\right)\end{array}$ & $\begin{array}{c}\text { Difference } \\
\Delta T=T_{\text {mod }}-T_{\exp }\end{array}$ \\
\hline \multirow{2}{*}{ Rotor bars } & \multirow{2}{*}{ Temperature } & with fan & 275.6 & 266.6 & $-9^{\circ} \mathrm{C}$ \\
\hline & & without fan & 251.3 & 259.9 & $+8.6^{\circ} \mathrm{C}$ \\
\hline \multirow{4}{*}{$\begin{array}{l}\text { Stator } \\
\text { end windings }\end{array}$} & \multirow{2}{*}{$\begin{array}{c}\text { Maximum } \\
\text { temperature } T_{\max }\end{array}$} & with fan & 251.0 & 237.1 & $-14^{\circ} \mathrm{C}$ \\
\hline & & without fan & 225.8 & 225.7 & $-0.1^{\circ} \mathrm{C}$ \\
\hline & \multirow{2}{*}{$\begin{array}{c}\text { Difference } \\
\Delta T=T_{\max }-T_{\min }\end{array}$} & with fan & 79.7 & 2.9 & 1 \\
\hline & & without fan & 66.1 & 3.3 & I \\
\hline
\end{tabular}

TABLE 3 Comparison of temperature results between experiments and model - Coils Load operation conditions at $2200 \mathrm{rpm}$

\begin{tabular}{|c|c|c|c|c|c|c|}
\hline & $\begin{array}{l}\text { Operation } \\
\text { conditions }\end{array}$ & $\begin{array}{l}\text { Rotational } \\
\text { speed (rpm) }\end{array}$ & $\begin{array}{l}\text { Stator Ducts } \\
(\%)\end{array}$ & $\begin{array}{c}\text { Convection } \\
(\%)\end{array}$ & $\begin{array}{l}\text { Radiation } \\
(\%)\end{array}$ & $\begin{array}{l}\text { Conduction } \\
\text { into the shaft } \\
(\%)\end{array}$ \\
\hline \multirow{3}{*}{ Experiments } & \multirow{6}{*}{ Load } & 2200 & 88.2 & 8.4 & 3.4 & - \\
\hline & & 3010 & 91.1 & 6.3 & 2.6 & - \\
\hline & & 3550 & 90.5 & 7.0 & 2.5 & - \\
\hline \multirow{4}{*}{ Model } & & 2200 & 55.9 & 28.9 & - & 15.2 \\
\hline & & 3010 & 54.4 & 23.5 & - & 22.1 \\
\hline & & 3550 & 49.2 & 19.9 & - & 30.9 \\
\hline & No-load & 3010 & 48.7 & 22.0 & - & 29.3 \\
\hline
\end{tabular}

TABLE 4 Heat fluxes distribution 